\title{
Effect of bonding pressure on microstructure and mechanical properties of aluminium/copper diffusion-bonded joint
}

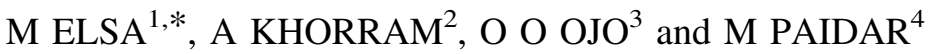 \\ ${ }^{1}$ Qazvin Science and Technology Park, Qazvin 34149-16818, Iran \\ ${ }^{2}$ Faculty of Mechanical Engineering, K.N. Toosi University of Technology, Tehran, Iran \\ ${ }^{3}$ Department of Industrial and Production Engineering, Federal University of Technology Akure, Akure, Nigeria \\ ${ }^{4}$ Department of Material Engineering, South Tehran Branch, Islamic Azad University, Tehran 1459853849, Iran \\ e-mail: mortez.elsa@gmail.com
}

MS received 18 December 2018; revised 25 February 2019; accepted 27 February 2019; published online 29 April 2019

\begin{abstract}
Pressure pulsation is notable for improving diffusion bonding process by breaking oxide layer present at the faying metal surfaces while an increased bonding pressure is envisaged to produce more compressive deformation (squeezing effect) on the reaction layer. This work aims at improving inter-atomic intersperse and mechanical properties of $\mathrm{Al} / \mathrm{Cu}$ joint via the control of the bonding-compressive pressure. The bonding temperature $\left(600{ }^{\circ} \mathrm{C}\right)$ and time $(60 \mathrm{~min})$ were kept constant while the bonding pressure was varied between 5 and 12.5 MPa. The metallurgical and mechanical properties of the joint were studied. The results revealed that an oxide-free bond interface was produced in a pressure range of 5-12.5 MPa. The rise in the bonding pressure (5-12.5 MPa) increases the bond strength (78.39-108.47 MPa) and the diffusion depth $(11.32-20.87 \mu \mathrm{m})$ between the $\mathrm{Al} / \mathrm{Cu}$ interfaces. Five (5) distinctive regions having $\mathrm{CuAl}_{2.4}, \mathrm{Al}_{1.3} \mathrm{Cu}_{3.1} \mathrm{Sn}$, $\mathrm{Al}_{2.5} \mathrm{Cu}_{1.5} \mathrm{Sn}, \mathrm{CuAl}_{1.8}$ and $\mathrm{AlCu}_{2.3} \mathrm{Sn}_{1.4}$ phases were formed within the reaction layer due to the varying level of interspersing/inter-atomic diffusion. Maximum hardness increases with bonding pressure level towards the $\mathrm{Cu}$ side from 57 to $111 \mathrm{HV}$ due to the precipitation of $\mathrm{Al}_{2.5} \mathrm{Cu}_{1.5} \mathrm{Sn}$ and $\mathrm{AlCu}_{2.3} \mathrm{Sn}_{1.4}$ phases.
\end{abstract}

Keywords. Aluminium; copper; diffusion bonding; microstructure; mechanical properties; diffusion; bonding pressure.

\section{Introduction}

The combined attributes of $\mathrm{Al}$ and $\mathrm{Cu}$ such as low density and corrosion resistance of $\mathrm{Al}$, and electrical conductivity of $\mathrm{Cu}$, are being sought for in modern manufacturing [1] $\mathrm{Al} / \mathrm{Cu}$ structural joints can satisfy the electrical and thermal requirement, cost and weight-saving demands required in modern applications such as electric vehicles (electromobility), and electrical power transmission units of automobiles, aircraft structures and high-speed train. The strong chemical affinity between $\mathrm{Al}$ and $\mathrm{Cu}$ enforces the formation of $\mathrm{Al}_{x} \mathrm{Cu}_{y}$ intermetallic compounds (IMCs), which are detrimental to electrical conductivity and strength [2]. The interatomic bonds within $\mathrm{Al}_{x} \mathrm{Cu}_{y}$ IMCs (between $\mathrm{Al}$ and $\mathrm{Cu}$ ) reduce the number of available free electrons needed for thermal conductivity, reduce ductility and give additional hardening effect to the joint interface [1]. Higher electrical resistivity is thus promoted by the level of IMCs in the $\mathrm{Al} / \mathrm{Cu}$ joint. The diversities in the physiochemical properties (melting point and thermal expansion coefficient) of $\mathrm{Al}$ and $\mathrm{Cu}$ metals promote the susceptibility of

*For correspondence
$\mathrm{Al}_{x} \mathrm{Cu}_{y}$ IMCs in $\mathrm{Al} / \mathrm{Cu}$ joints [3]. Conventional welding methods are inappropriate for joining $\mathrm{Al} / \mathrm{Cu}$ [4-6] owing to the intense requisite heat input. High-integrity dissimilar $\mathrm{Al} / \mathrm{Cu}$ joint with the least detrimental effect of IMCs can be obtained with the diffusion bonding process [7]. The interdiffusion of atoms across the surfaces of $\mathrm{Al}$ and $\mathrm{Cu}$ at a reduced temperature can produce sound and quality joint [7].

The mechanisms for atomic movement and growth of IMC were studied via dislocation-assisted diffusion by Gholamirad et al [8]. It was reported that dislocations strongly controlled diffusional processes that lead to the growth of IMCs. Shen et al [9] reported that the atomic migration of chemical species across interfaces (base metals) directly increased with increase in the levels of temperature and time. The different inherent diffusion coefficients of chemical species facilitate the formation of Kirkendall voids at the interfaces of the base metals [10]. Aydin et al [11] reported that an increase in the diffusion area was promoted by increasing the bonding temperature and time. Different diffusion rates at the interfacial region promoted the Kirkendall effect. Eslami and Taheri [12] studied the diffusional bond between $\mathrm{Cu}$ sheath and $\mathrm{Al}$ 
core. It was revealed that many grain boundaries (finegrained microstructure) acted as short-circuit paths for diffusion during the bonding process. Grain boundary migration was predominantly faster in the fine-grained materials when compared with that of coarse-grained. Thermal residual stresses and thickness of interaction layer between $\mathrm{Al} / \mathrm{Cu}$ joints can be minimized using interlayer foils as stress relieving elements [13, 14].

The interfacial zone (ITZ) of dissimilar $\mathrm{Al} / \mathrm{Cu}$ bonded materials consists of different reaction layers having IMCs and it has been affirmed that the thickness of these layers increases with the operating temperature [5]. Intensive diffusion bonding ensues during the heat treatment process [15]. Mahendran et al [4] revealed that bonding temperature has a dominant effect on bond characteristics. Optimum diffusion layer was attained at a bonding temperature, pressure and time of $450{ }^{\circ} \mathrm{C}, 12 \mathrm{MPa}$ and $30 \mathrm{~min}$, respectively [4]. The layers close to $\mathrm{Al}$ and $\mathrm{Cu}$ base metals were composed of $\mathrm{Al}_{2} \mathrm{Cu}$ and $\mathrm{Al}_{4} \mathrm{Cu}_{9}$, respectively, while a reasonably thin middle layer of $\mathrm{AlCu}$ and $\mathrm{Al}_{3} \mathrm{Cu}_{4}$ was formed in the $\mathrm{Al} / \mathrm{Cu}$ joint [1]. Zhou et al [16] revealed that the weld zone of $\mathrm{Al} / \mathrm{Cu}$ joint primarily consists of the $\alpha-\mathrm{Al}$ solid solution and coral-like shaped $\mathrm{Al}-\mathrm{Cu}$ eutectic phase. The increase in the thickness of $\mathrm{Al}_{2} \mathrm{Cu}$ layer increased the shear strength of the joint. Dugal and Ciappa [17] showed that thermal aging of the bonded joint (at $150{ }^{\circ} \mathrm{C}$ ) reduced the bond strength with time. Degradation of the interdiffusion layer was reported to impair the bond strength after the thermal aging process. Xiong et al [2] reported that thick, hard and brittle intermetallic/reaction layer at the interface of $\mathrm{Al}-\mathrm{Cu}$ and $\mathrm{Al}-\mathrm{Ag}-\mathrm{Cu}$ joints promoted interfacial crack. Brittle and cleavage fracture mode was promoted by the presence of $\mathrm{Al}_{3} \mathrm{Mg}_{2}$ brittle phase in the bonded joint of 7075/AZ31 [5].

Sufficient atomic migration and complete metallurgical bond can be obtained by having appropriate parameter combination levels among bonding time, temperature and applied pressure [11]. The effects of parameters such as temperature and time have been examined on the diffusion bonding characteristics of lightweight metals [18-20]. A few research works have been carried out on the effect of pressure pulsation while the role of bonding pressure on bond delamination, oxidation and void formation still needs to be thoroughly accessed. Thus, this work studies the effect of bonding pressure on the compressive deformation of the reaction layer between $\mathrm{Al} / \mathrm{Cu}$ interfaces. The mechanical and microstructural properties of the bond interface were studied via the use of a scanning electron microscope (SEM) and energy-dispersive X-ray (EDS).

\section{Materials and method}

The base materials employed for this work were pure $\mathrm{Al}$ and $\mathrm{Cu}$ alloys. The chemical compositions of the alloys are shown in tables 1 and 2. The alloys were cut into the
Table 1. The chemical composition of pure copper (wt $\%)$.

\begin{tabular}{lcccc}
\hline $\mathrm{Cu}$ & $\mathrm{Zn}$ & $\mathrm{Pb}$ & $\mathrm{Al}$ & $\mathrm{Fe}$ \\
\hline 99.98 & $<0.00010$ & 0.0025 & 0.0037 & 0.00043 \\
\hline
\end{tabular}

Table 2. The chemical composition of pure aluminium (wt $\%$ ).

\begin{tabular}{cccccccc}
\hline $\mathrm{Al}$ & $\mathrm{Fe}$ & $\mathrm{Cu}$ & $\mathrm{Si}$ & $\mathrm{Mn}$ & $\mathrm{Mg}$ & $\mathrm{Zn}$ & $\mathrm{Ti}$ \\
\hline 99 & 0.4 & 0.05 & 0.25 & 0.05 & 0.05 & 0.05 & 0.03 \\
\hline
\end{tabular}

dimensions of $10 \times 10 \times 5 \mathrm{~mm}^{3}$, ground and polished with different sizes grits. The polished surfaces of the alloys were subjected to ultrasonic cleaning in acetone to remove fine metal residues/contaminants from the prepared surfaces. The two alloys were placed on top of each other with a $100 \mu \mathrm{m}$ thick tin (Sn) foil as an interlayer between the alloys (see figure 1). The prepared $\mathrm{Al}$ and $\mathrm{Cu}$ surfaces together with the Sn interlayer formed an interfacial contact zone. A fixture was employed to apply uniaxial pressures of 5,8 and $12.5 \mathrm{MPa}$ on the workpiece arrangements. Diffusion bonding was carried out in a furnace subjected to a vacuum pressure, temperature and bonding time of $10^{-2}$ mbar, $600{ }^{\circ} \mathrm{C}$ and $60 \mathrm{~min}$, respectively. A schematic illustration of the applied pressures on the workpiece arrangement is shown in figure 2 .

The diffusion-bonded samples were transversely cut to obtain the metallographic samples. The samples were polished and etched in Keller's reagent to reveal the microstructure of the joint interface. An optical microscope and a SEM equipped with EDS were utilized to characterize the $\mathrm{Al} / \mathrm{Cu}$ bonded or joint interface. Vickers microhardness test was carried out on the joint with a diamond indenter of load $50 \mathrm{~g}$ and dwell time of $10 \mathrm{~s}$. The shear
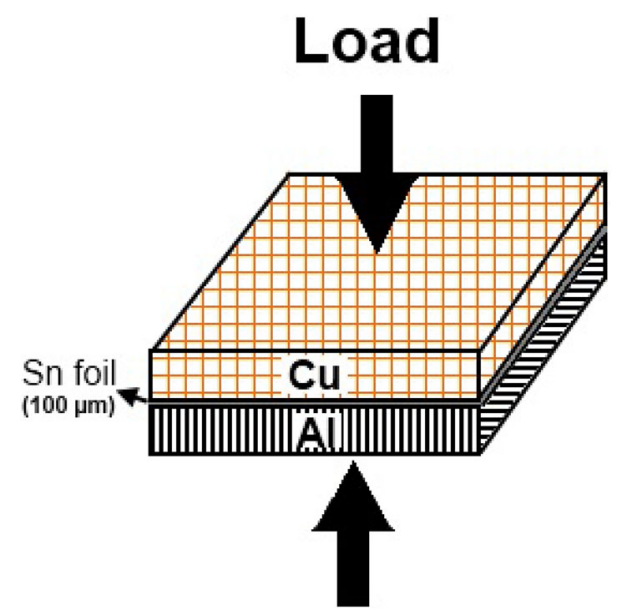

Figure 1. Schematic illustration of $\mathrm{Al}, \mathrm{Cu}$ and $\mathrm{Sn}$ foil during diffusion bonding. 


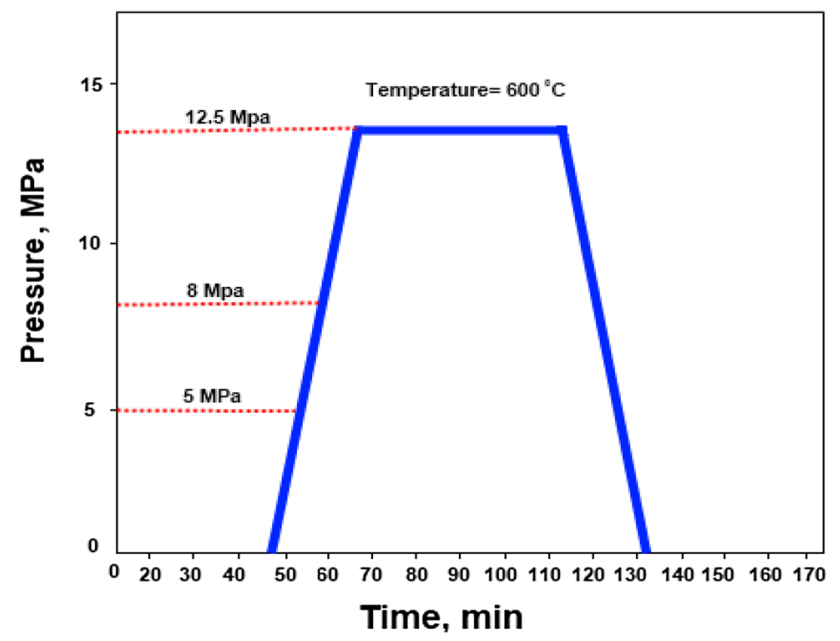

Figure 2. Schematic illustration of the applied pressures on the workpiece.

strength test of the bonded samples was carried out according to ASTM E229-97 standards on a MTS30/MH tensile testing machine at a cross-head speed of $1 \mathrm{~mm} / \mathrm{min}$.

\section{Results and discussion}

\subsection{Microstructure}

Figure 3 shows the bonded interfacial region of the $\mathrm{Al} / \mathrm{Cu}$ joint. Overlays of interaction layers are obvious at the interfacial region between the $\mathrm{Al}$ and $\mathrm{Cu}$ substrates (see figure $3 \mathrm{a}$ ). The whitish region in figure $3 \mathrm{a}$ ensues due to the effect of high $\mathrm{Sn}$ solubility in $\mathrm{Cu}$ [19]. Mapped analysis of the interfacial region is conducted in order to understand the level of diffusion among the overlaid interaction layers. The mapped image of the bonded region (see figure $3 \mathrm{~b}$ ) reveals that inter-diffusion between $\mathrm{Al}$ and $\mathrm{Cu}$ substrates ensues at the interfacial bonded region of the joint. The diffusion of $\mathrm{Cu}$ element (red colouration) into the $\mathrm{Al}$ substrate is more pronounced in figure $3 \mathrm{~b}$ as against that of $\mathrm{Al}$. Red colouration $(\mathrm{Cu}$ element) is observed in the adjacent region of the bulk $\mathrm{Al}$ substrate; this confirms the level of $\mathrm{Cu}$ diffusion within the bonded region. Varmazyar and Khodaei [21] reported that such a gradual increase in the $\mathrm{Cu}$ concentration from the $\mathrm{Al}$ side to the $\mathrm{Cu}$ side was an indication of atomic diffusions required for the bonding process. The diffusion of $\mathrm{Al}$ element (green colouration) is palpable over a few microns on the top of the bulk Al substrate. This indicates that the adjacent reaction layer close to the $\mathrm{Al}$ substrate is rich in $\mathrm{Al}$ content and the level of $\mathrm{Al}$ element (green colouration) decreases away from the bulk $\mathrm{Al}$ metal/substrate towards the $\mathrm{Cu}$ side.

Figure 4 shows the interaction layer formed due to the inter-diffusion between $\mathrm{Al}$ and $\mathrm{Cu}$ as the bonding pressure level is increased. The disparity of diffusion coefficients/ rates (between $\mathrm{Al}$ and $\mathrm{Cu}$ ) did not cause any notable Kirkendall void in the bonded zone of the $\mathrm{Al} / \mathrm{Cu}$ joint as the bonding pressure was increased (see figure 4). The increase in the bonding pressure level improved the diffusion depth or thickness of the interaction layer at the $\mathrm{Al} / \mathrm{Cu}$ interface. The interaction layer's thicknesses of 11.32, 15.25 and $20.87 \mu \mathrm{m}$ were obtained at pressure levels of 5,8 and $12.5 \mathrm{MPa}$, respectively. This observation confirms that an increase in the bonding pressure level facilitates more interdiffusion of elements and spontaneous chemical reaction within the adjacent region of the interfacial surfaces (of $\mathrm{Al}$ and $\mathrm{Cu}$ substrates). This phenomenon is attributed to the intensified surface-to-surface contact within the interfacial region of the metals ( $\mathrm{Al}$ and $\mathrm{Cu}$ ) as the bonding pressure is increased [20]. The established difference between the surface free energies was reported to be the driving force of diffusion [19] between the $\mathrm{Al}$ and $\mathrm{Cu}$ metals. Intense
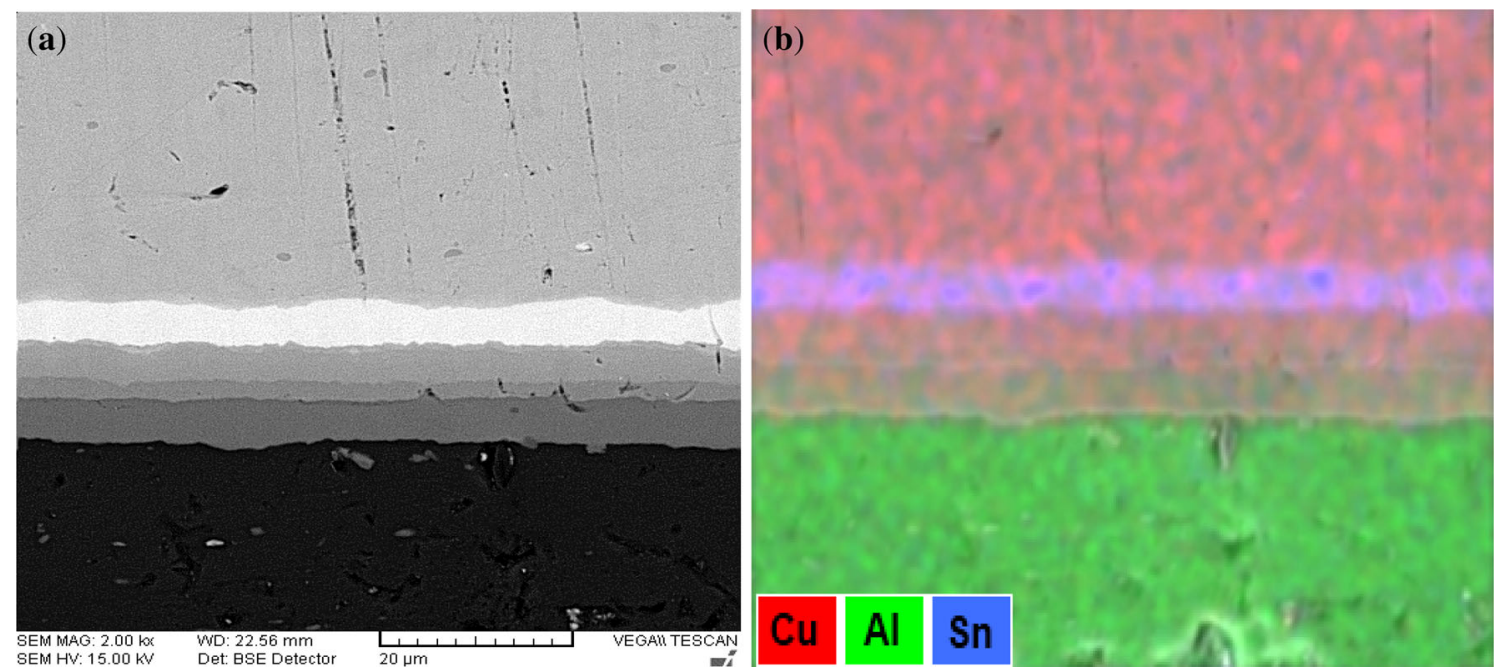

Figure 3. SEM images of the interfacial joint: (a) unmapped image and (b) mapped image. 

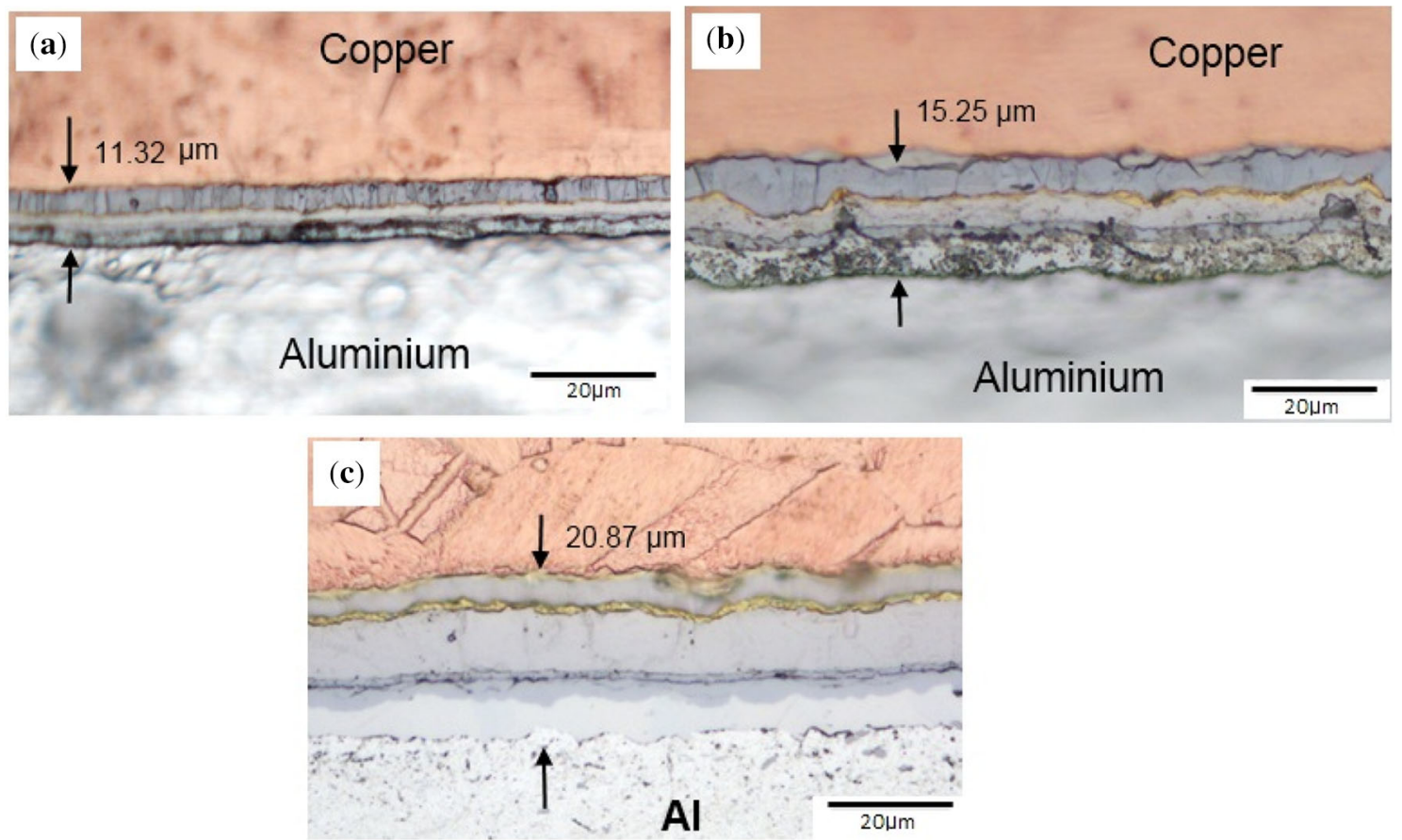

Figure 4. Effect of bonding pressure on the thickness of the interaction layer at (a) $5 \mathrm{MPa}$, (b) $8 \mathrm{MPa}$ and (c) $12.5 \mathrm{MPa}$.

surface-to-surface contact owing to greater squeezing effect (bonding pressure) facilitates atomic motion or inter-diffusion of elements (between $\mathrm{Al}$ and $\mathrm{Cu}$ ) to establish a more pronounced and progressive increase in the reaction layers or thicknesses of the bonded areas. Although squeezing action (compression effect) is expected to be enforced on the established intermetallic or reaction layer in the joint's interfacial region, more diffusion of elements into the adjacent regions of the $\mathrm{Al}$ and $\mathrm{Cu}$ substrates ensues (owing to the increase in the bonding pressure level). Equally, the rate of reaction in the joint's interfacial region could be said to have increased with the bonding pressure level (at constant bonding time). This might have caused the consistent growth or spreading of the interaction layer (increase in the thickness of the reaction layer) into the $\mathrm{Al}$ and $\mathrm{Cu}$ substrates as the bonding pressure was increased.

Close-up views of the reaction layers (in figure 4) are shown in figure 5. According to figure 5, the established reaction layer within the $\mathrm{Al} / \mathrm{Cu}$ joint is divided into five unique regions (A-E). Region $\mathrm{A}$ is the reaction area/segment adjacent to the $\mathrm{Al}$ substrate while region $\mathrm{C}$ is the closest region to the $\mathrm{Cu}$ substrate. Regions $\mathrm{B}, \mathrm{D}$ and $\mathrm{E}$ lie within the core of the reaction layer (with regions $\mathrm{E}$ and $\mathrm{D}$ closer to the $\mathrm{Cu}$ and $\mathrm{Al}$ sides, respectively). Evidence of lateral delamination is observed to occur at the interfacial regions of $\mathrm{A} / \mathrm{D}$ and $\mathrm{C} / \mathrm{E}$. This suggests that shear stresses are high enough in these bonded areas owing to the applied pressure to cause delamination. On the other hand, composition gradient owing to inter-diffusion (between $\mathrm{Al}$ and $\mathrm{Cu}$ ) promotes diffusion-induced stress in the interfacial joint zone. This phenomenon naturally causes strain mismatch and eventual lateral or joint surface delamination. High bonding pressure enforces faster inter-diffusion, increases the reaction layer and the potential strain mismatch within the inter-diffused $\mathrm{Al}$ and $\mathrm{Cu}$ bond to give way for lateral delamination (observed in figure 5). Razazi et al [22] reported that large inherent precipitates greatly affect decohesion resistance in the as-cast Al-Mn alloy. It can be adjudged that the higher interaction layer/width (assisted by an increase in bonding pressure) promotes decohesion within the formed reaction layer, which eventually leads to the observed lateral delamination (in figure 5). The critical assessment of the identified regions is thus considered to be essential.

The EDS analyses of the identified regions were carried out to ascertain their exact compositions. The EDS spectra of the points are shown in figure 6. Regions A (70.75 wt\% $\mathrm{Al}$ and $29.25 \mathrm{wt} \% \mathrm{Cu})$ and $\mathrm{B}(63.85 \mathrm{wt} \% \mathrm{Al}$ and $36.15 \mathrm{wt} \% \mathrm{Cu}$ ) are predominated by the presence of $\mathrm{Al}$ and $\mathrm{Cu}$ elements without the trace of Sn. According to the Al$\mathrm{Cu}$ binary phase diagram, $\alpha$ and $\theta\left(\mathrm{CuAl}_{2}\right)$ phases are the possible phases in regions $\mathrm{A}$ and $\mathrm{B}$. On the other hand, regions $\mathrm{B}, \mathrm{C}$ and $\mathrm{E}$ have $\mathrm{Al}$ and $\mathrm{Cu}$ contents together with Sn contents of $18.85,19.98$ and $30.18 \mathrm{wt} \%$, respectively. There is a high possibility of ternary $\mathrm{Al}-\mathrm{Cu}-\mathrm{Sn}$ phases in these regions ( $\mathrm{B}, \mathrm{C}$ and $\mathrm{E})$. However, the EDS results confirm the high rate of Sn solubility and diffusion into the $\mathrm{Cu}$ side (owing to the amount of $\mathrm{wt} \% \mathrm{Sn}$ in regions $\mathrm{C}$ and E). $\mathrm{Cu}$ offers no barrier to the diffusion of $\mathrm{Sn}$ atoms into it [19]. Table 3 shows summarized EDS results and the 


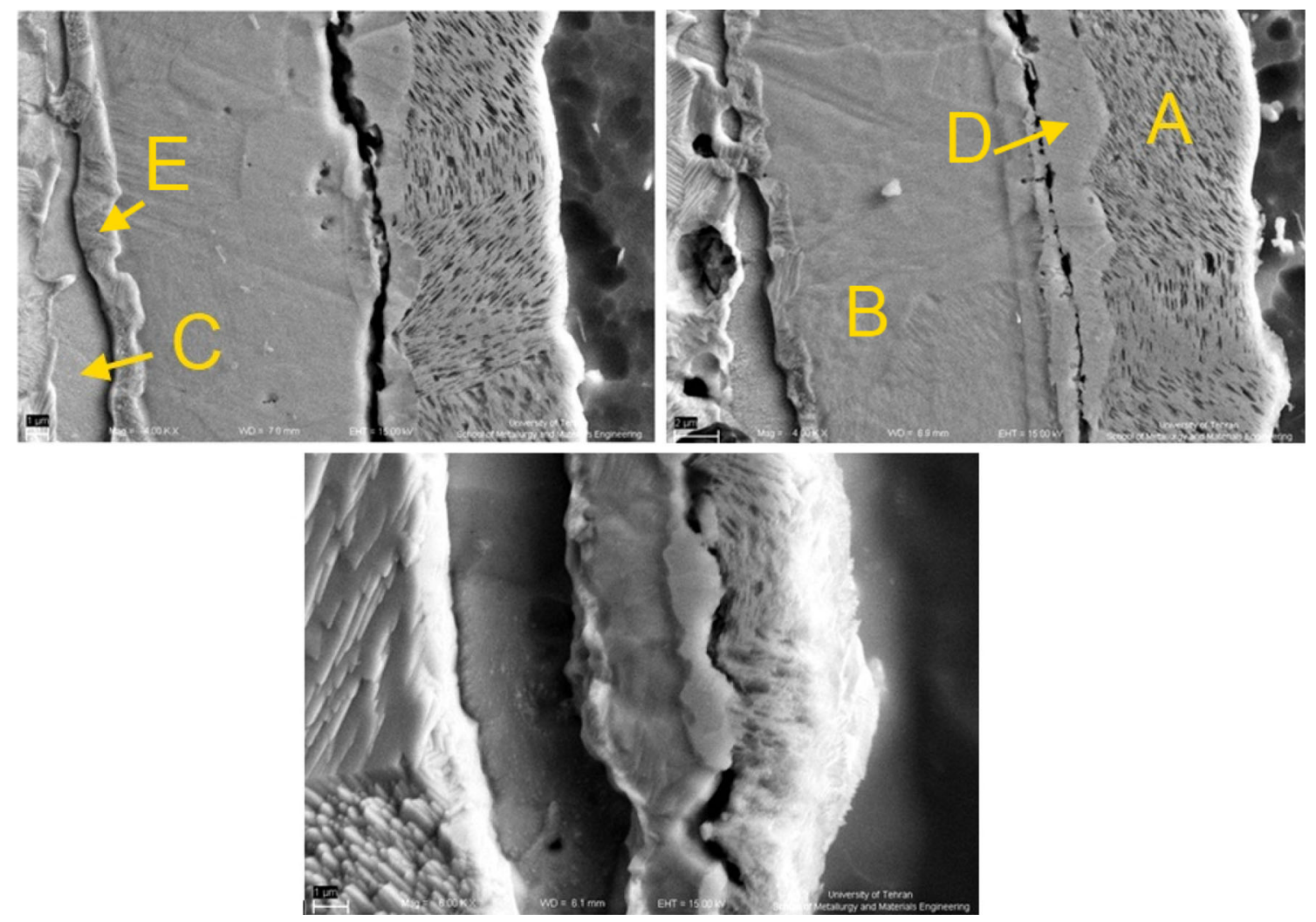

Figure 5. Close-up views of reaction layers between $\mathrm{Al}$ and $\mathrm{Cu}$ substrates.

possible phases in the identified regions. The results show that an oxide-free bonded zone ( $\mathrm{Al} / \mathrm{Cu}$ interface) ensues as $\mathrm{Al} / \mathrm{Cu}$ substrates are subjected to the axial bonding pressure. Regions A, B, C, D and $\mathrm{E}$ consist of $\mathrm{CuAl}_{2.4}, \mathrm{Al}_{1.3-}$ $\mathrm{Cu}_{3.1} \mathrm{Sn}, \mathrm{Al}_{2.5} \mathrm{Cu}_{1.5} \mathrm{Sn}, \mathrm{CuAl}_{1.8}$ and $\mathrm{AlCu}_{2.3} \mathrm{Sn}_{1.4}$ phases, respectively. The possible uneven atomic inter-diffusion and the presence of uneven chemical compositions across the interfacial regions of $\mathrm{A} / \mathrm{D}\left(\mathrm{CuAl}_{2.4} / \mathrm{CuAl}_{1.8}\right)$ and $\mathrm{C} / \mathrm{E}$ $\left(\mathrm{Al}_{2.5} \mathrm{Cu}_{1.5} \mathrm{Sn} / \mathrm{AlCu}_{2.3} \mathrm{Sn}_{1.4}\right)$ could be responsible for the observed lateral delamination in figure 5. These regions (A/ $\mathrm{D}$ and $\mathrm{C} / \mathrm{E}$ ) can be adjudged to have significant shear stress (capable of causing delamination) under axial bonding pressure. Afghahi et al [5] revealed that an increase in bonding pressure (10-35 MPa) caused a significant amount of plastic deformation in the diffusion-bonded joint of 7075/AZ31. An optimum pressure of $25 \mathrm{MPa}$ was acknowledged to produce the minimum amount of plastic deformation at the joint.

\subsection{Mechanical properties}

The hardness distribution across the transverse section of the $\mathrm{Al} / \mathrm{Cu}$ bond interface is shown in figure 7. An improvement of hardness is observed at the bond centre as the bonding pressure level is increased from 5 to $12.5 \mathrm{MPa}$. The hardness at the centre of the bond interface increased from 16 to $42.68 \mathrm{HV}$ owing to the increment in the bonding pressure. Likewise, the maximum hardness values at the $\mathrm{Cu}$ and $\mathrm{Al}$ sides increased from 57 to $111.18 \mathrm{HV}$ and 27-51 HV, respectively, due to the rise in the bonding pressure level. The improvement of hardness at the $\mathrm{Cu}$ side (regions $\mathrm{C}$ and $\mathrm{E}$ ) is attributed to the precipitation of hard phases of $\mathrm{Al}_{2.5} \mathrm{Cu}_{1.5} \mathrm{Sn}$ and $\mathrm{AlCu}_{2.3} \mathrm{Sn}_{1.4}$ in regions $\mathrm{C}$ and $\mathrm{E}$, while the presence of $\mathrm{CuAl}_{2.4}$ and $\mathrm{CuAl}_{1.8}$ slightly improved the hardness of the $\mathrm{Al}$ side when compared with that of the bond centre.

Sharma and Dwivedi [23] reported that grain refinement (at the bonding interface) was induced by the compressive deformation owing to the bonding pressure pulsation. The compressive deformational effect on the joint interface increased the grain boundary area, quickened inter-diffusion at the bonded zone and increased the hardness at the diffusion bond interface. This phenomenon is considered to be responsible for the improved hardness across the bond interface as the bonding pressure is increased.

Figure 8 shows the effect of bonding pressure on the failure load of the $\mathrm{Al} / \mathrm{Cu}$ joint. An increase in the bonding pressure improves the failure resistance of the bonded joint. Joint strength of $78.39,98.24$ and $108.47 \mathrm{MPa}$ was obtained at bonding pressure levels of 5,8 and $12.5 \mathrm{MPa}$, respectively. This occurrence is due to the increase in the diffusion of atoms around the adjoining interface. The increase in the bonding pressure facilitates adequate 


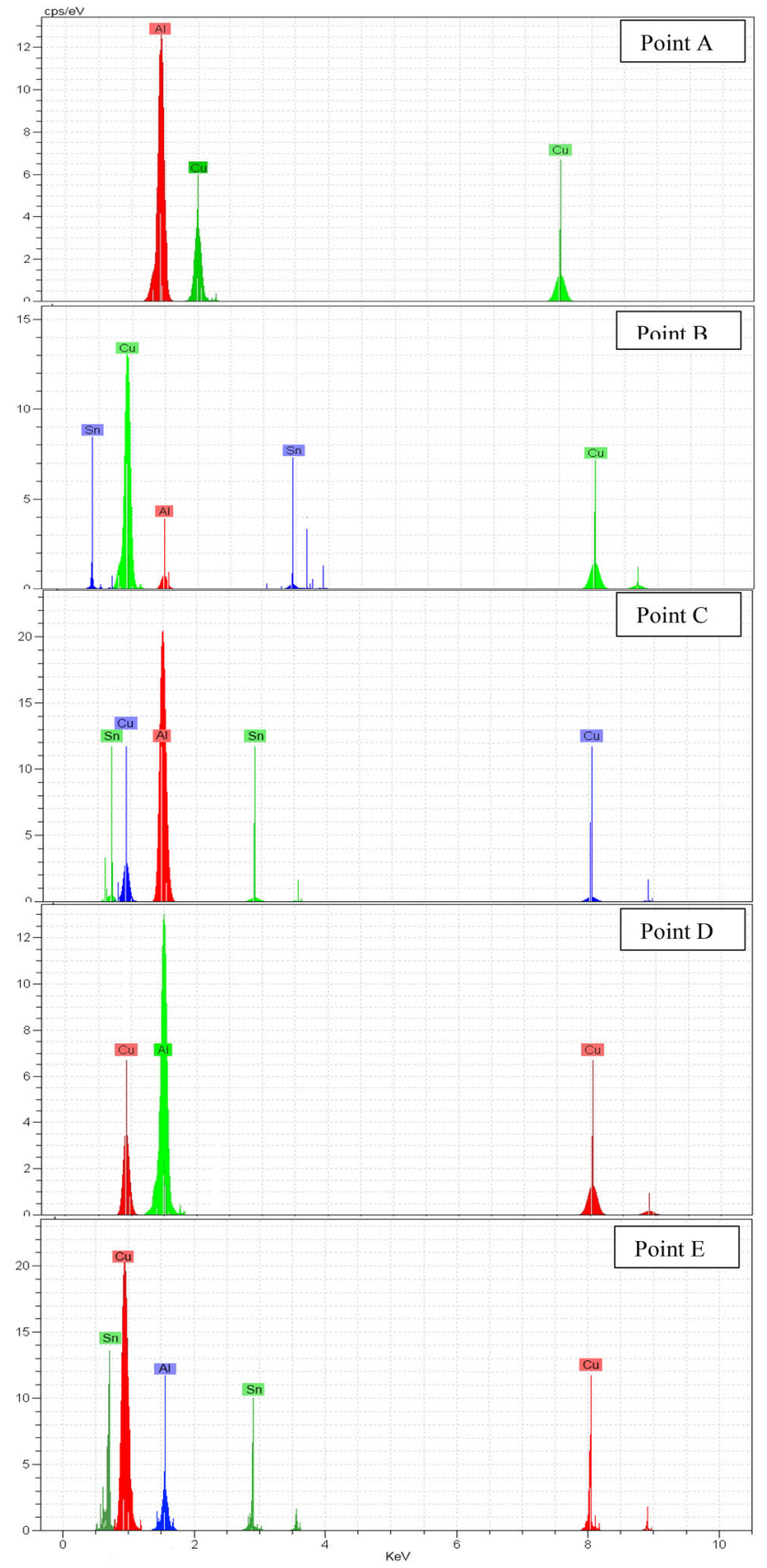

Figure 6. EDS spectra of the marked points/regions.

Table 3. Summarized EDS results for the marked regions.

\begin{tabular}{lcccc}
\hline Regions/points & $\begin{array}{c}\mathrm{Al} \\
(\mathrm{wt} \%)\end{array}$ & $\begin{array}{c}\mathrm{Cu} \\
(\mathrm{wt} \%)\end{array}$ & $\begin{array}{c}\mathrm{Sn} \\
(\mathrm{wt} \%)\end{array}$ & $\begin{array}{c}\text { Possible } \\
\text { IMCs }\end{array}$ \\
\hline A & 70.75 & 29.25 & 0 & $\mathrm{CuAl}_{2.4}$ \\
B & 23.57 & 57.58 & 18.85 & $\mathrm{Al}_{1.3} \mathrm{Cu}_{3.1} \mathrm{Sn}$ \\
$\mathrm{C}$ & 49.57 & 30.45 & 19.98 & $\mathrm{Al}_{2.5} \mathrm{Cu}_{1.5} \mathrm{Sn}$ \\
D & 63.85 & 36.15 & 0 & $\mathrm{CuAl}_{1.8}$ \\
E & 21.45 & 48.37 & 30.18 & $\mathrm{AlCu}_{2.3} \mathrm{Sn}_{1.4}$ \\
\hline
\end{tabular}

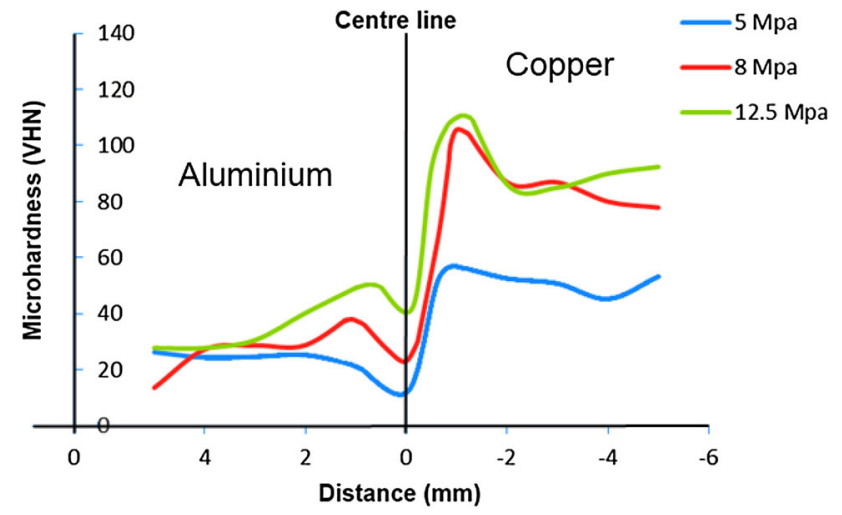

Figure 7. Microhardness values across the bonded joint.

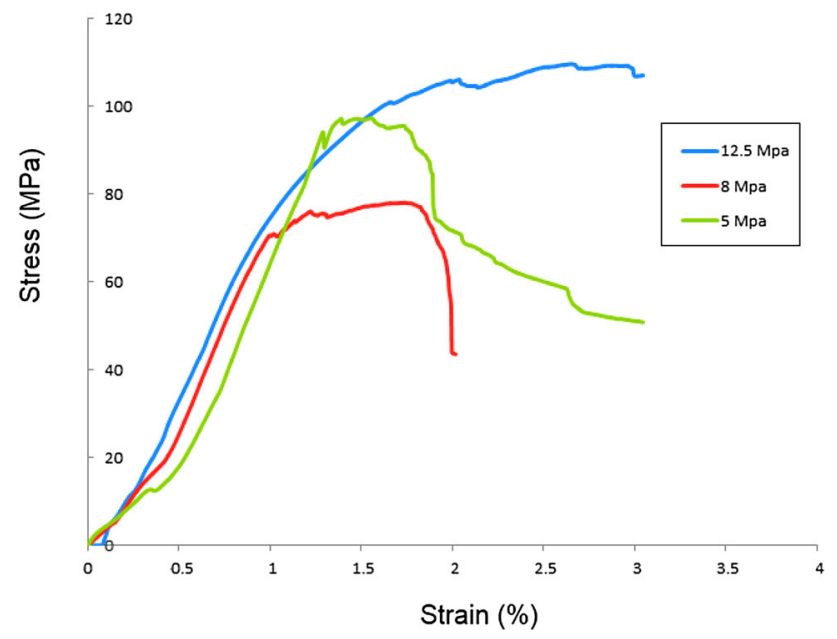

Figure 8. Failure load as a function of the bonding pressure.

interspersion of atoms and increases the diffusion depth at the $\mathrm{Al} / \mathrm{Cu}$ joint. The increase in the diffusion layer width improved bond strength in the works of Varmazyar and Khodaei [21]. This phenomenon is adjudged to be responsible for the improved strength or failure load observed in figure 8 (as the pressure level is increased).

An increase in the bonding pressure or pressure pulsation has been reported to help in breaking the oxide layer present at the faying surfaces and consequently improve the diffusion process [23]. The increase in the bonding pressure produces more compressive deformation on the reaction layer at the bond interface and this has been adjudged to inhibit the formation of void at the bond interface [23]. These phenomena could be responsible for the improved joint strength as the bonding pressure was increased. Assari and Eghbali [18] reported that the application of uniform pressure during hot press bonding produced excellent contact surfaces between $\mathrm{Al}$ and $\mathrm{Ti}$ (produced good $\mathrm{Al} / \mathrm{Ti}$ bond), and promoted the inhibition of cracks and voids at the bond interface. Similarly, Ojo et al [24] revealed that 


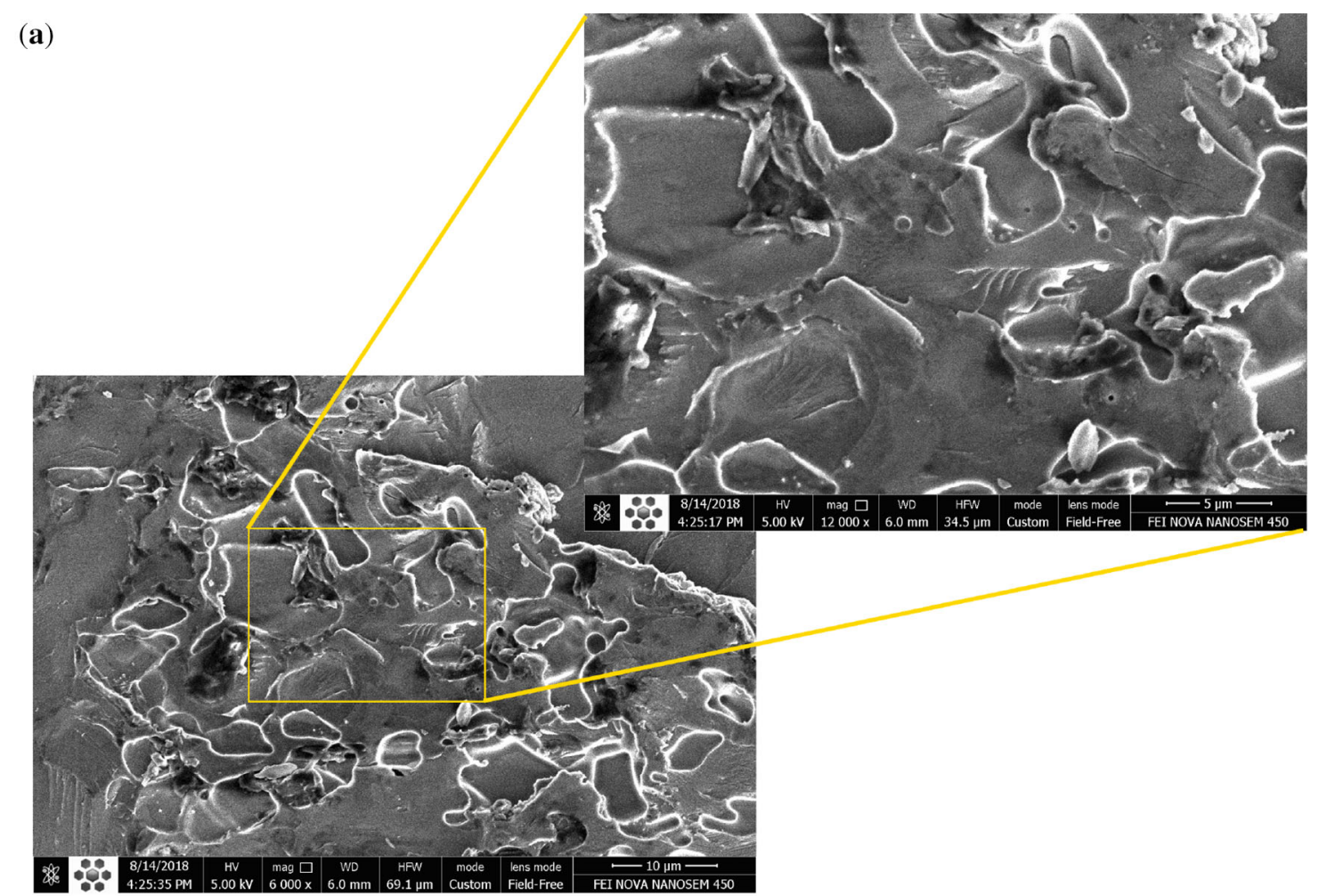

(b)

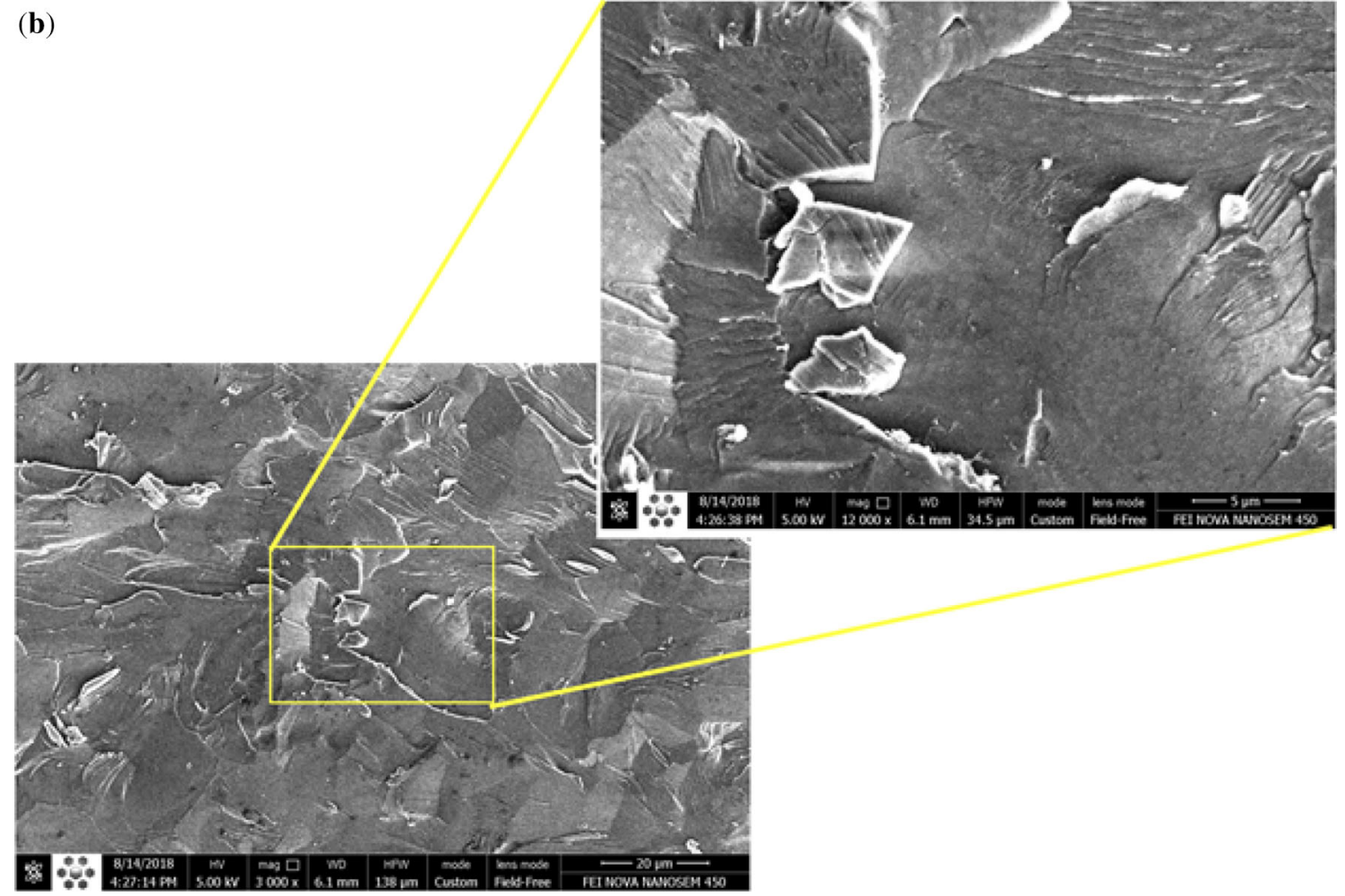

Figure 9. FESEM images of fracture surfaces: (a) $5 \mathrm{MPa}$ and (b) $12.5 \mathrm{MPa}$.

the effective bonded width between the upper and lower plates plays a dominant role in the fracture resistance of weld during axial loading. The increase in bonding pressure could have improved the bonded width between the $\mathrm{Al}$ and $\mathrm{Cu}$ alloys and caused the improved strength (78.39-108.47 MPa) of the diffusion-bonded $\mathrm{Al} / \mathrm{Cu}$ joint. 
On the other hand, the presence of lateral delamination at the bond interface could have impaired the load carrying capacity of the diffusion bond interface but the increase in bonding pressure still increased the failure resistance of the joint. Other stress concentrators like voids are not present at the bond interface and this observation may likely be responsible for the improved strength (as the bonding pressure level is increased). Sharma and Dwivedi [23] reported that the interface bonding ratio of diffusion bonds was improved by pressure pulsation as compared with that of bonds produced at constant pressure level. The improvement in the bond was attributed to the reduced voids at the bond interface.

All the bonded $\mathrm{Al} / \mathrm{Cu}$ joints failed through the bond interfaces (fracture location) due to the presence of IMCs and intrinsic lateral delamination at the interfacial region. Weld failure has been attributed to crack growth by shear localization [25] and by the presence of stress concentration sites such as defective weld regions (weakest regions) [26]. The latter appears to predominate in the examined joint because all joint failures ensue through the region with lateral delamination (interfacial region). Figure 9 shows the FESEM images of the fracture surface. The topographic details on the fracture surfaces show that the joints fail via brittle fracture patterns owing to the intermetallic phases and stress concentration at the bond interface. Figure 9a reveals the occurrence of brittle and cleavage fracture mode. The presence of brittle fracture ridges in figure $9 \mathrm{~b}$ could have been influenced by the presence of lateral delamination in the bond interface. The region with interfacial de-bonding or lateral delamination acts as a stress concentration site during axial loading, interfacial/cleavage shearing occurs overtime and final failure path consequently ensues in the defective region (with lateral delamination).

\section{Conclusion}

Diffusion bonding between $\mathrm{Al}$ and $\mathrm{Cu}$ metals was successfully carried out under varying bonding pressure conditions. The following findings were observed:

1. The bonding pressure range of 5-12.5 MPa produced an oxide-free bonded zone between the $\mathrm{Al} / \mathrm{Cu}$ joint.

2. The diffusion depth at the $\mathrm{Al} / \mathrm{Cu}$ interface directly increases with a rise in the bonding pressure level due to the intensified surface-to-surface contact within the interfacial $\mathrm{Al} / \mathrm{Cu}$ region. Diffusion depths of 11.32 , 15.25 and $20.87 \mu \mathrm{m}$ were obtained at bonding pressure levels of 5, 8 and $12.5 \mathrm{MPa}$, respectively.

3. The reaction layer within the $\mathrm{Al} / \mathrm{Cu}$ interface consists of five (5) unique regions having $\mathrm{CuAl}_{2.4}, \mathrm{Al}_{1.3} \mathrm{Cu}_{3.1} \mathrm{Sn}$, $\mathrm{Al}_{2.5} \mathrm{Cu}_{1.5} \mathrm{Sn}, \mathrm{CuAl}_{1.8}$ and $\mathrm{AlCu}_{2.3} \mathrm{Sn}_{1.4}$ phases. The varying level of interspersing or inter-atomic diffusion within the reaction layer was responsible for the formation of these phases.
4. An increase in bonding pressure level together with uneven atomic inter-diffusions promotes the formation of lateral delamination at the interfaces of $\mathrm{CuAl}_{2.4}$ / $\mathrm{CuAl}_{1.8}$ and $\mathrm{Al}_{2.5} \mathrm{Cu}_{1.5} \mathrm{Sn} / \mathrm{AlCu}_{2.3} \mathrm{Sn}_{1.4}$ phases.

5. The increase in the bonding pressure level improves the hardness values across the bond interface. The precipitation of $\mathrm{Al}_{2.5} \mathrm{Cu}_{1.5} \mathrm{Sn}$ and $\mathrm{AlCu}_{2.3} \mathrm{Sn}_{1.4}$ phases towards the $\mathrm{Cu}$ side improves the maximum hardness value from 57 to $111 \mathrm{HV}$ as the bonding pressure is increased from 5 to $12.5 \mathrm{MPa}$.

6. The resistance to failure of the bonded $\mathrm{Al} / \mathrm{Cu}$ joint improves as the bonding pressure is increased from 5 to 12.5 MPa. Joint strength of 78.39, 98.24 and 108.47 $\mathrm{MPa}$ was obtained at bonding pressures of 5, 8 and $12.5 \mathrm{MPa}$, respectively. The improved strength was attributed to the increase in the diffusion depth at the interface of the $\mathrm{Al} /$ $\mathrm{Cu}$ joint as the pressure level was increased.

7. The fracture surfaces reveal brittle and cleavage fracture modes.

$\begin{array}{ll}\text { Nomenclature } \\ \text { ASTM } & \text { American Society for Testing and Materials } \\ \text { EDS } & \text { energy-dispersive X-ray } \\ \text { FESEM } & \text { field emission scanning electron microscope } \\ \text { IMCs } & \text { intermetallic compounds } \\ \text { ITZ } & \text { interfacial zone } \\ \text { SEM } & \text { scanning electron microscope }\end{array}$

\section{References}

[1] Lee K S and Kwon Y-N 2013 Solid-state bonding between $\mathrm{Al}$ and $\mathrm{Cu}$ by vacuum hot pressing. Trans. Nonferrous Met. Soc. China 23: 341-346

[2] Xiong J, Peng Y, Zhang H, Li J and Zhang F 2018 Microstructure and mechanical properties of $\mathrm{Al}-\mathrm{Cu}$ joints diffusion bonded with $\mathrm{Ni}$ or Ag interlayer. Vacuum 147: 187-193

[3] da Silva T H, E B Nelson, Williamson I, Efaw C M, Sapper E, Hurley M F and Li L 2018 First-principles surface interaction studies of aluminum-copper and aluminum-coppermagnesium secondary phases in aluminum alloys. Appl. Surf. Sci. 439: 910-918

[4] Mahendran G, Balasubramanian V and Senthilvelan T 2010 Influences of diffusion bonding process parameters on bond characteristics of $\mathrm{Mg}-\mathrm{Cu}$ dissimilar joints. Trans. Nonferrous Met. Soc. China 20: 997-1005

[5] Afghahi S S S, Jafarian M, Paidar M and Jafarian M 2016 Diffusion bonding of Al 7075 and Mg AZ31 alloys: process parameters, microstructural analysis, and mechanical properties. Trans. Nonferrous Met. Soc. China 26: 1843-1851

[6] Ureiia A, Gomez de Salazar J M and Escalera M D 1996 Diffusion bonding of an aluminum-copper alloy reinforced with silicon carbide particles (AA2014/SiC/13p) using metallic interlayers. Scr. Mater. 35: 1285-1293 
[7] R J G R Nimal, Sivakumar M, Raj S G, Vendan S A and Esakkimuthu G 2018 Microstructural, mechanical and metallurgical analysis of $\mathrm{Al}$ interlayer coating on $\mathrm{Mg}-\mathrm{Al}$ alloy using diffusion bonding. Mater. Today Proc. 5: 5886-5890

[8] Gholamirad M, Soltani S and Sepehrband P 2018 Dislocation assisted diffusion: a mechanism for growth of intermetallic compounds in copper ball bonds. Microelectron. Reliab. 81: 210-217

[9] Shen Q, Xiang H, Luon G, Wang C, Li M and Zhang L 2014 Microstructure and mechanical properties of TC4/oxygenfree copper joint with silver interlayer prepared by diffusion bonding. Mater. Sci. Eng. A 596: 45-51

[10] Sabetghadam H, Hanzaki A Z and Araee A 2010 Diffusion bonding of 410 stainless steel to copper using a nickel interlayer. Mater. Charact. 61(2010): 626-634

[11] Aydın K, Kaya Y and Kahraman N 2012 Experimental study of diffusion welding/bonding of titanium to copper. Mater. Des. 37: 356-368

[12] Eslami P and Taheri A K 2011 An investigation on diffusion bonding of aluminum to copper using equal channel angular extrusion process. Mater. Lett. 65: 1862-1864

[13] Yang Z H, Shen Y F, Wang Z Y and Cheng J L 2014 Tungsten/steel diffusion bonding using $\mathrm{Cu} / \mathrm{W}-\mathrm{Ni} / \mathrm{Ni}$ multiinterlayer. Trans. Nonferrous Met. Soc. China 24: 2554-2558

[14] Simoes S, Viana F, Ramos A S, Vieira M T and Vieira M F 2016 Reaction-assisted diffusion bonding of TiAl alloy to steel. Mater. Chem. Phys. 171: 73-82

[15] Chmura W and Gronostajski Z 2007 Bearing materials obtained by diffusion bonding of aluminum and aluminum bronze chips. Arch. Civil. Mech. Eng. 3: 53-66

[16] Zhou X, Zhang G, Shi Y, Zhu M and Yang F 2017 Microstructures and mechanical behavior of aluminumcopper lap joints. Mater. Sci. Eng. A 705: 105-113
[17] Dugal F and Ciappa M 2017 Reliability investigation of the copper-zinc system for solid diffusion bonding in power modules. Microelectron. Reliab. 76-77: 460-464

[18] Assari A H and Eghbali B 2019 Solid state diffusion bonding characteristics at the interfaces of Ti and Al layers. J. Alloys Compd. 773: 50-58

[19] Safarzadeh A, Paidar M and Youzbashi-Zade H 2016 A study on the effects bonding temperature and holding time on mechanical and metallurgical properties of $\mathrm{Al}-\mathrm{Cu}$ dissimilar joining by DFW. Trans. Indian Inst. Met. 70: 125-131

[20] Samavatian M, Zakipour S and Paidar M 2016 Effect of bonding pressure on microstructure and mechanical properties of Ti-6Al-4V diffusion-bonded joint. Weld. World 61: 69-74

[21] Varmazyar J and Khodaei M 2019 Diffusion bonding of aluminum-magnesium using cold rolled copper interlayer. $J$. Alloys Compd. 773: 838-843

[22] Razazi H A, Paidar M and Ojo O O 2018 Effect of Mn and $\mathrm{Cr}$ on structure and mechanical properties of $\mathrm{Al}-10 \% \mathrm{Mg}-$ 0.1\% Ti alloy. Vacuum 155: 619-630

[23] Sharma G and Dwivedi D K 2017 Effect of pressure pulsation on bond interface characteristics of 409 ferritic stainless steel diffusion bonds. Vacuum 146: 152-158

[24] Ojo O O, Taban E and Kaluc E 2018 Loop travel-path of fibre laser welded Alclad AA2219-O alloy. J. Mater. Process. Technol. 251: 118-126

[25] Ojo O O and Taban E 2018 Hybrid multi-response optimization of friction stir spot welds: failure load, effective bonded size, and flash volume as responses. Sadhana 43: 98

[26] Ojo O O and Taban E 2018 Effect of residual Alclad on friction stir spot welds of AA2219 alloys. Mater. Test. 60: 979-988 